\title{
Systematic Classification of Colonic Crypts with Architectural Distortions Inulcerative Colitis
}

\author{
Carlos A Rubio $^{1 *}$, Lorand Kis ${ }^{1}$, Peter T Schmidt ${ }^{2}$ \\ ${ }^{I}$ Department of Pathology, Center for Digestive Disease, Karolinska Institute and University Hospital, \\ Stockholm, Sweden \\ ${ }^{2}$ Department of Medicine, Center for Digestive Disease, Karolinska Institute and University Hospital, \\ Stockholm, Sweden
}

*Corresponding Author: Carlos A Rubio, Department of Pathology, Center for Digestive Disease, Karolinska Institute and University Hospital, Stockholm, Sweden, Email: Carlos.Rubio@ki.se

\begin{abstract}
In ulcerative colitis (UC) the colonic mucosa shows in addition to high number of inflammatory cells, crypts with architectural distortions $(C A D)$. Here we classify the histologic repertoireand assess the frequency of CAD in UC. Five-hundred and sixteen histologic sections from 29 colectomy specimens with UC (24 having adenocarcinoma and five, high-grade dysplasia, HGD) were reviewed. CADs were subdivided into four groups: i) Crypts with fission distortions, ii) Crypts with length distortions, iii) Crypts with outlines distortions and iv) Crypts with axial polarity distortions. The most frequent CAD group hadaxial polarity distortions (33.4\%), and the less frequent CAD group, outline distortions $(21.1 \%)(P<0.05)$. No apparent differences in frequency between groups were found in colectomies with HGD/carcinoma, or in colectomies preformed for medically-refractory UC without HGD/carcinoma. Most mucosal areas, however, portrayed countless crypts with normal shapes (CNS) lined with normal epithelium, excepting 45 CNS: 28 showed in conclusive-suspected cellular changes (ISCC), and 17, HGD. In contrast, out of the 902 CAD present in the specimens, $343(38.0 \%)$ displayed ISCC, 186 (20.6\%) HGD, and the remaining 373 (41.4\%) normal epithelium. Hence, out of the 203 crypts exhibiting HGD, 186 (91.6\%) were CAD and the remaining 17 $(8.4 \%) C N S(P<0.05)$. Based on these findings it is suggested that the microscopic search for HGD in UC colectomy-specimens should preferentially be focused to mucosal areas exhibiting CAD. This view is validated by recent findings showing that p53 over expression (a biomarker of epithelialcarcinogenesis) significantly correlated with architectural distortions of the crypts in UC.
\end{abstract}

Keywords: ulcerative colitis, colonic crypts, aberrations, histology, phenotypes

\section{INTRODUCTION}

The normal colonic mucosa is built of a single layer of epithelial cells with inward folds called crypts. Crypts replicate by symmetric fission, beginning at their base, and proceeding upwards until two identical, individual crypts are created [1]. Sections cut perpendicular to the surface epithelium show a characteristic appearance of "row of test tubes" due to tightly packed, parallel crypts, "resting" on the muscular is mисоsae. A slight variation in the configuration of the crypts and in the space between the crypts may occur, but crypt branching is rare. This architecture is retained throughout the colon, except in in nominate grooves (cloverleaf-like crypts connecting to a single lumen) [1].In ulcerative colitis (UC) the colonic mucosa shows, in addition to high numbers of inflammatory cells, distortions of crypt architecture [2]. These architectural distortions usually persist despite regress of inflammation due to treatment. In some colitic patients however, architectural crypt irregularities enigmatically revert to normal after many years of disease, a setting referred to as with restitutioadintegrum $[3,4]$.

The architectural crypt irregularities in UC have received various descriptive terms such as architectural aberrations [5], architectural crypt distortion [6] ramification of the crypts [7] considerable branching at the base of the crypts [8], crypt bifurcations [9], and crypt architectural disarray [10], to name some. Nearly 30 years ago, Allen et al. used semiautomatic image analysis to assess the architectural features of colorectal mucosa in UC [11]. Discriminant analysis using the variables mean epithelial height and mean lamina propria area per unit length of muscular is mисоsae, separated normal from UC. 
Subsequently, Hamilton et al. appliedmorphometry and stereology, to evaluate the architectural characteristics of regenerative and of dysplastic colorectal mucosa in ulcerative colitis [12].Using neural networks on a mosaic of pixilated images (without any image analysis or image segmentation) the authors concluded that quantitative histological analysis of mucosal abnormalities may be of use in the objective diagnosis of reactive and dysplastic change in patients with ulcerative colitis [12]. More recently, Ficsor et al. [13] reported architectonic irregularities in the colonic

\section{Material AND MethodS}

Archival histological sections from 35 colectomies in patients with UC were reviewed. Six out of the 35 colectomies were rejected from the study: four due to partial mucosal autolysis and the remaining two due to partial faded stainability. In the remaining 29 colectomies, 516 histological sections (mean 17.8, range 1042 sections) were available for study. Sections were cut at $4 \mu \mathrm{m}$ thickness and stained with hematoxylin and eosin (H\&E). Three colectomyspecimens performed because of severe UC refractory to clinical treatment (without carcinoma or HGD) [14] were included as controls.

CAD were subdivided into four groups: $i$ ) Crypt-fission distortions, ii) Crypt-length distortions, III) Crypt-outline distortions, and iv) Crypt-axial polarity distortions (in relationship to the muscular is mucosae).

The epithelial lining in CAD displayed the following features:

a) Normal epithelium,

b) Inconclusive or suspected cellular changes (ISCC), ranging from cell regeneration to possibly low-grade dysplasia. CAD lined with ISCC were often seen in areas with chronic- active inflammation, with ulcerated mucosa or with severe chronic inflammation without acute inflammation,

c) High-grade dysplasia (HGD, as define by Riddell et al [15].

Not with standing, the vast majority of the colonic crypts both in areas with or without chronic inflammation, exhibited normal shapes (CNS) lined with normal epithelium. However, some CNS were lined with in conclusive or suspected cellular changes (ISCC), and others with unequivocal high-grade dysplasia (HGD) [15]. mucosa by the aid of automated digital microscopy and advanced digital analysis. Shape-related morphological changes helped to distinguish between normal mucosa and UC. However, despite those studies, the systematic analysis of the spectrum of crypts with architectural distortions (CAD) in UC, has remained unattended.

The purpose of this communication was to classify and to assess the frequency of CAD found in a cohort of colectomy specimen from patients with UC.

Statistical analysis. The non-parametric KruskalWallis test was applied, to compare difference between groups. Statistical significance was defined as $\mathrm{P}<0.05$.

This study was approved by the Ethical Committee of the Karolinska Institute No.2017/1657-32

\section{RESUlts}

\subsection{Clinical Data}

\subsubsection{Gender}

Twenty-two were males and the remaining seven, females

\subsubsection{Age}

The mean age at colectomy was 48.1 years (range 32-65 years)

\subsubsection{No. of Years with UC Prior Surgery}

The mean number of years with UC prior surgery was 20.7 (range 10-32 years).

\subsection{Histological Findings}

The histological examination of the 29 colectomy specimens revealed adenocarcinoma in 24 and high-grade dysplasia in the remaining five.

The histological evaluation also revealed a total of $902 \mathrm{CAD}$ in the 29 colectomy specimens (mean 31.1 CAD/colectomy, range 22-48). Two or more histologic phenotypes were found in each group:

Group1. (Crypts with fission distortions) included asymmetric crypt fissions and cystic crypts (Figure 1) 


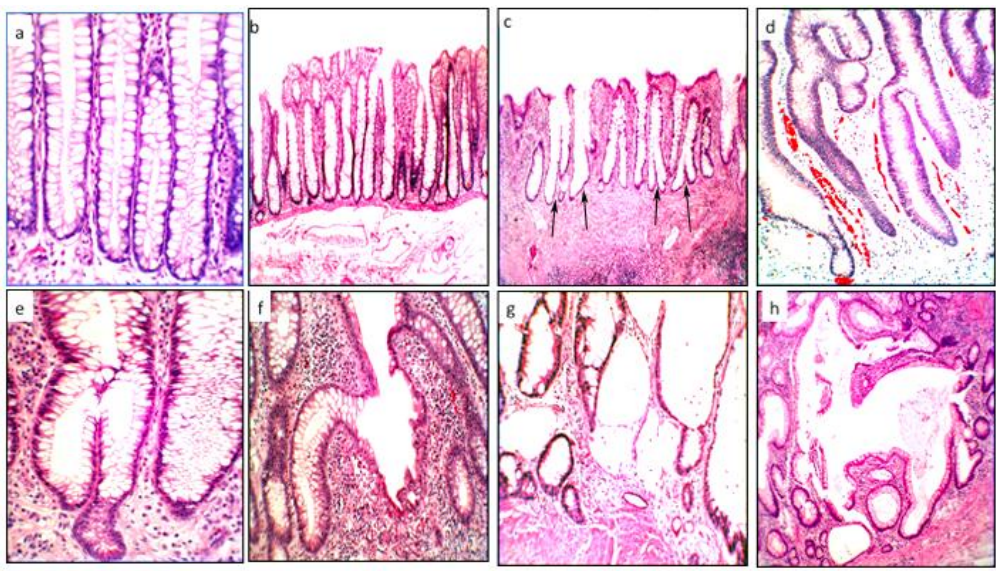

Figure1. Colonic crypts with fission distortions in ulcerative colitis a: Normal colonic mucosa (for comparison) showingtightly packed, parallel crypts "resting" on the muscularis mucosae, H\&E x20, b: Colonic mucosa with mild chronic inflammation having parallel crypts resting on the muscularis mucosae, $H \& E x 4$, c:Colonic mucosa with expanded lamina propria due to severe chronic inflammation. Note colonic crypts withasymetricfissionat arrows $H \& E x 4, d$ : Colonic crypts with asymmetric fission(one crypt seems to have "lost a shoe", H\&E x20), $f$ : Colonic crypts with asymmetric fission(H\&E x20), g: Colonic crypts with cystic dilatations, (H\&E x10), h:Colonic crypt with "deer-like” cystic dilatation (H\&E x10).

Group2. (Crypts with length distortions), comprised hyperplastic crypts and atrophic crypts (Figure2)

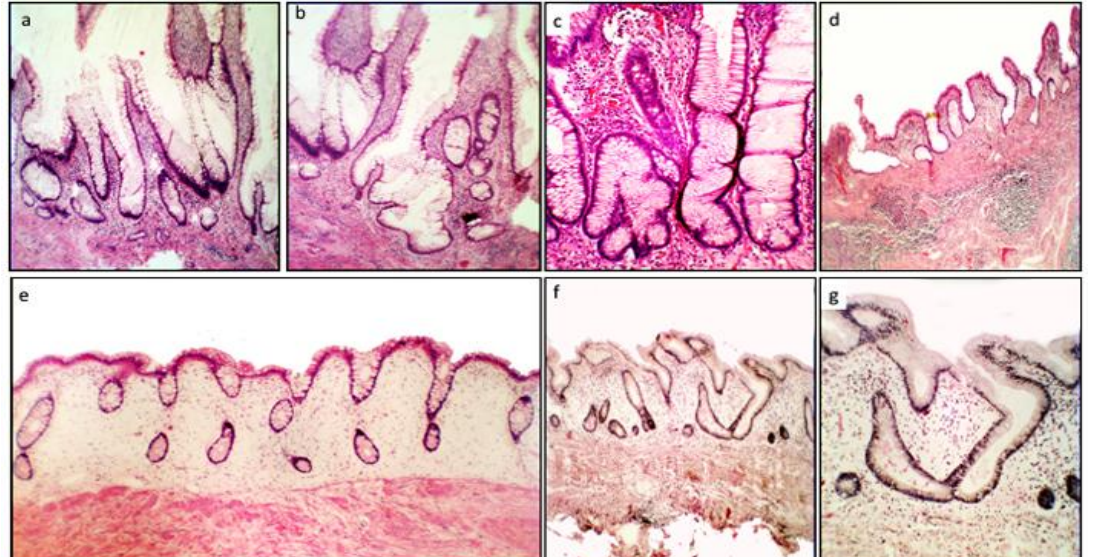

Figure2. Colonic crypts with length distortions in ulcerative colitis $\boldsymbol{a}, \boldsymbol{b}:$ Hyperplasticcolonic crypts with asymmetric fission (H\&E $x 44)$, c: Hyperplasticcolonic crypts $H \& E x 4)$. d-f: Hypoplastic-atrophic colonic crypts(H\&E x4), g: UC in remission with two "merging” atrophic crypts (H\&E x 10).

Group3. (crypts with outline distortions) crypts with: i) serrated outlines, andii) encompassed mullti-lobate-scalloped crypts, and microtubular outlines (Figure 3), and

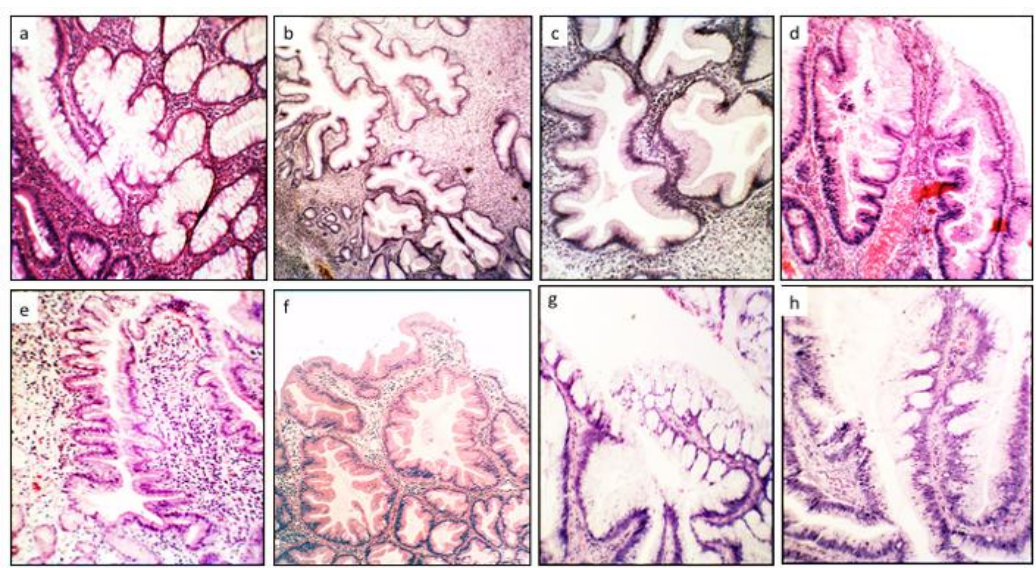

Figure3. Colonic crypts with outline distortions in ulcerative colitis a:Mullti-lobate crypts (H\&E x10), b: Crypts with scalloped architecture $(H \& E x 4)$, c:Detail of bto highlight the scalloped architecture $(H \& E x 20), \boldsymbol{d}$ f: Crypts with serrated architecture (H\&E x10, $x 4$ and $x 4$, respectively.), $\mathrm{g}$-h:Crypts withscallop (microtubularlike)architecture (H\&€ $\times 4)$. 
Group4. (Crypts with axial polarity distortions in relation to the muscularis mucosae), included meandering-serpentine crypts, inter communicating crypts, ring-shaped crypts, inverted L shapes and horizontal ring-shaped crypts (Figure 4 and 5).

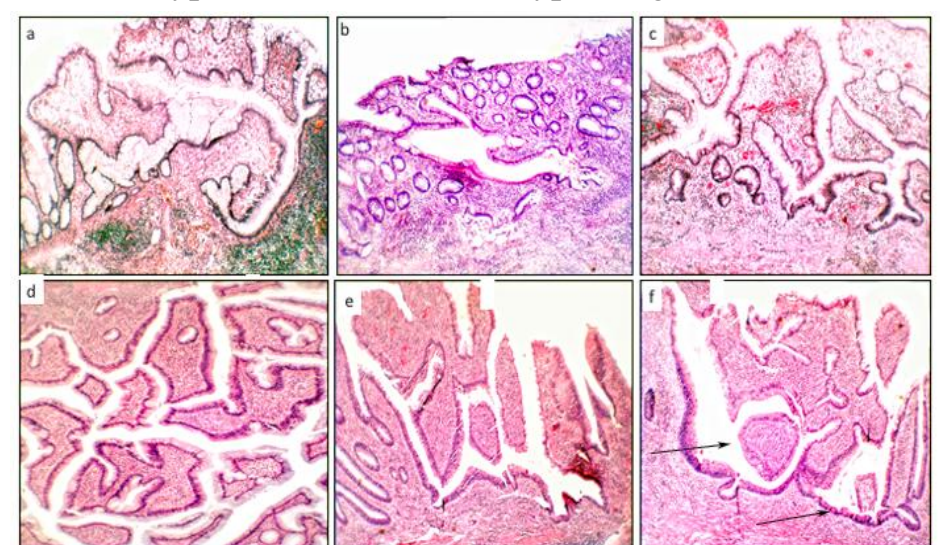

Figure4. Colonic crypts with axial polarity distortions in relation to the muscularis mucosae) in ulcerative colitis a-e: Meandering-intercommunicating crypts, several with axial polarity distortions (H\&E x4), $f:$ Ringshaped crypts, at arrows (H\&E x4).

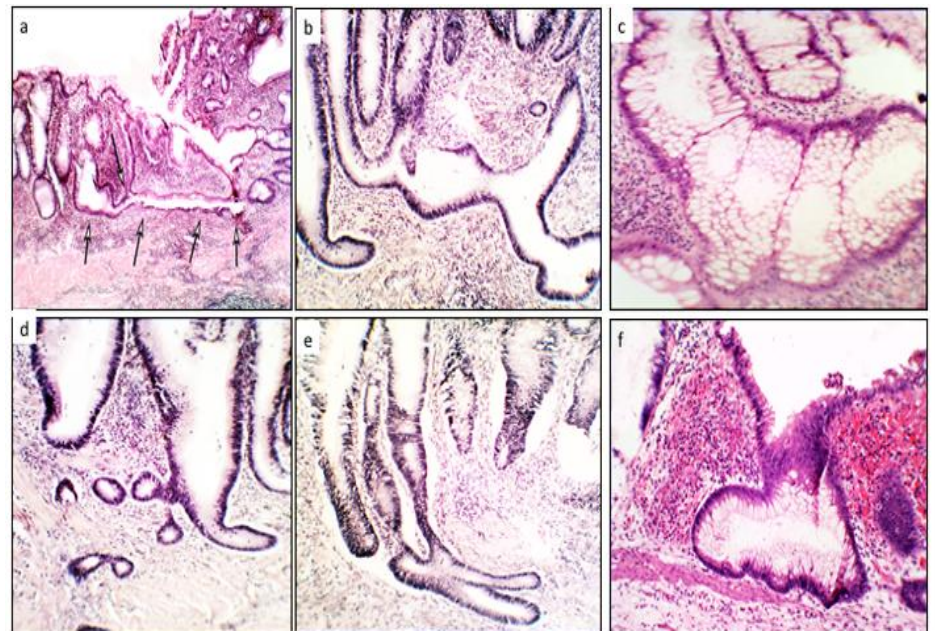

Figure5. Colonic crypts with axial polarity distortions in relation to the muscularis mucosae) in ulcerative colitis $\boldsymbol{a}$ : Intercommunicating crypts with axial polarity distortions (at arrows, H\&E x4), b: Long crypt parallel with the muscularis mucosae (H\&E x10), c: Detail from another long horizontal crypt with "ring-accretions" (H\&E x20), d: Horizontal epithelial "rings" at arrows (H\&E, x10), e: Crypt with inverted L (showing fission distortion (H\&E x 10), f: "shoe-shaped" crypt found bordering regenerating ulcer (H\&E, x20)

The most frequent CAD -groups (33.4\%), portrayed crypt axial-polarity distortions (in relationship to the muscular is mисоsae), and

Table1. The frequency of histologic groups of crypts with architectural distortions (CAD) found in 29 colectomy specimens in patients with ulcerative colitis having carcinoma $(n=24)$, or high-grade dysplasia $(n=5)$. Three additional colectomy specimens performed because of severe UC refractory to clinical treatment (without carcinoma or HGD) are also shown.

\begin{tabular}{|l|l|l|}
\hline \multicolumn{1}{|c|}{$\begin{array}{c}\text { Groups with architectural crypt } \\
\text { distortions(ACD) }\end{array}$} & \multicolumn{1}{|c|}{$\begin{array}{c}\text { 29 colectomies* } \\
\text { No. ACD (percent) }\end{array}$} & \multicolumn{1}{c|}{$\begin{array}{c}\text { Three colectomies } \\
\text { No. ACD (percent) }\end{array}$} \\
\hline Distortions in crypt fission & 242 & 20 \\
& $(26.8 \%)$ & $(28.6 \%)$ \\
\hline Distortions in crypt length & 190 & 16 \\
& $(21.1 \%)$ & $(22.9 \%)$ \\
\hline Distortions in crypt outlines & $\begin{array}{l}|c| \\
(169)\end{array}$ & 14 \\
& $301 \%)$ & $20.0 \%)$ \\
\hline $\begin{array}{l}\text { Distortions in axial polarity of crypts } \\
\text { (in relationship to themuscularis } \\
\text { mucosae) }\end{array}$ & $(33.4 \%)$ & $(28.6 \%)$ \\
\hline All & 902 & 70 \\
& $(100 \%)$ & $(100 \%)$ \\
\hline
\end{tabular}

the less frequent CAD-groups (18.7\%), cryptoutline distortions $(\mathrm{P}<0.05)$. (cfr. Table1). 


\subsubsection{Epithelial Lining in CAD}

Out of a total of 902 CAD, 373 (41.4\%) had normal epithelial lining, $343(38.0 \%)$ ISCA and the remaining 186 (20.6\%), HGD (Figure 6). CAD with normal epithelium/ISCA vs. HGD, $\mathrm{P}<0.05)$.

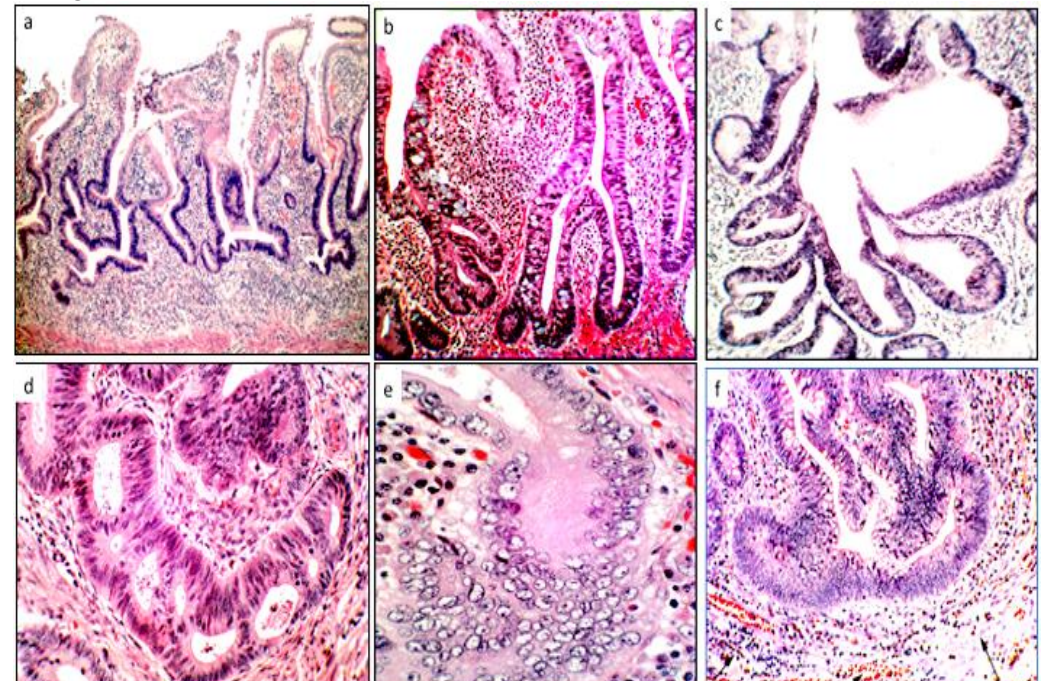

Figure6. Colonic crypts with various phenotypes of architectural distortions having high-grade dysplasia in ulcerative colitis a: Note that the dysplasia includes the lower half of the crypts having severe architectural distortions (H\&E, x4), b: Dysplasia in crypts with asymmetric fission (H\&E x10), : Dysplasia in a multi-lobate crypt with asymmetric fission (H\&E x4), d:Dysplasia in agglutinated tubules in a row with axial polarity distortion (H\&E x20), e, $f$ : Detail of high-grade dysplasia in crypts with architectural distortions $(H \& E, x 20)$.

Hence, out of the 203 colonic crypts with HGD 186 (91.6\%) occurred in CAD and the remaining $178 \quad(4 \%)$ in $\mathrm{CNS}(\mathrm{P}<0.05)$. inconclusive-suspected cellular changes (ISCC),

\subsubsection{Epithelial Lining in CNS}

The specimens had innumerable CNS lined with normal epithelium, in areas with or without inflammation. However, out of 45 CNS, 28 had ISCA and the remaining 17, HGD.

\section{DISCUSSION}

The systematic analysis of the spectrum of the colonic crypts with abnormal configurations, called CAD, was carried out in colectomy specimens with UC. The analysis revealed a high number of $\mathrm{CAD}$ exhibiting a wide gamut of architectural phenotypes. Rationally, crypts with or namentation distortions should had been generated by the chronic inflammation. And yet, large mucosal areas with chronic inflammation in the specimens had none to occasional CAD. In similarity with these findings, none to occasional CAD had been found in other colonic diseases with chronic inflammation such as diverticular disease-associated colitis [16], diversion colitis [17], lymphocytic colitis [18], radiation colitis [19], collagenous colitis [20], ischemic colitis [21], chronic colitis in Behçet's disease [22] and non-specific ulcers of the colon [23]. A rational explanation for these findings might be that CAD in UC were generated by factors other than ongoing chronic mucosal inflammation; one possible candidate might be an abnormal mucosal regeneration in areas with formerly mucosal denudation. In this context, CAD were recently found in mucosal areas bordering regenerating UC ulcers [14]. Why the process of mucosal regeneration severely alters the colonic crypts surrounding ulcers in colitic patients, remains enigmatic. Nevertheless, since chronic mucosal inflammation per se might not be crucialfor the development of CAD [16-23], we are prone to speculate that the $\mathrm{CAD}$ found in the non-ulcerated colonic mucosa in UC could represent abnormal crypt regeneration in areas with formerly mucosal ulcerations in colitic patients [14].

The significance of ISCA, often found in CAD in UC, remains challenging. This since McKenna and Appel man [24] postulated that the category 'indefinite for dysplasia' is an honest recognition of the difficulties in distinguishing reactive or regenerative epithelium from low-grade dysplasia. Moreover, studying inter-observer variation between pathologists regarding the degree of dysplasia in UC, Eadenet al. [25] found total concordance of the 13 pathologists in only four of the 51 slides. Agreement was best for high-grade dysplasia. Based on those findings we opted for classifying crypts with regenerative, 'indefinite for dysplasia' or low-grade dysplasia [24] as with 
inconclusive or suspected cellular changes (ISCC), and those with HGD (the histological phenotype less amenable to diagnostic disagreement)[25].

In conventional colonic adenomas, HGD initially develops at the luminal aspect of the crypts and progress downwards, towards the base of the crypts [26]. In UC, in contrast, dysplasia initially develops at the base of the crypts and progresses upwards, towards the luminal aspect of the crypts [27].In CAD, we found normal epithelial lining in $>40 \%$, ISCC in $38 \%$ and HGD in $>20 \%$. The finding that HGD was often found in the lower aspect of the CADs, appears to be in concert with the "bottom-up" replacement concept, conveyed by up-growing dysplastic cells in UC [29]. Based on these considerations, it is not inconceivable thatCAD might act as scaffolds at the time of "bottom-up" replacement by up-growing mutated dysplastic cells, a notion previously advanced in experimental animals [28]. The finding of serrated and micro tubular configurations with normal epithelial lining in CAD (cfr. Figure 3) supports the "dysplasticreplacement-of-the-crypts" concept, inasmuch as serrated adenomas and micro tubular adenomas do eventually evolve in patients with UC [29-33].

In a recent work, Popp et al. [34] found over expression of p53 -a tissue biomarker of epithelial carcinogenesis- in sections of UC patients. The authors found that architectural distortion significantly correlated with p53 over expression[34].The results of Popp et al. [34]seem to be in concert with the present findings,inasmuch as HGD in UC mainly occurred in crypts with architectural distortions (here referred to as CAD).

It should be understood that innumerable CNS lined with normal epithelium were found in areas with and without inflammation, excepting for 45 CNS displaying ISCC or HGD.

While cellular descriptions and molecular signals that control cell proliferation and cell mutations during carcinogenesis in UC have received much attention [35-41] the signals that might be instrumental in choreographing morphogenesis [42] resulting in the "etching" of various CAD phenotypes in UC, have remained unexplored.

In closing, one possible practical implication of the present findings might be that the microscopic search for HGD in UC-colectomies should primarily be focused to mucosal areas exhibiting CAD. This notion is validated by recent findings showing that p53 over expression (a biomarker of epithelial carcinogenesis) significantly correlated with architectural distortions of the crypts in UC [34]

\section{REFERENCES}

[1] D Levine and RC Haggittin Histology for Pathologists Ed Stephen Sternberg Raven Press,New York, USA, 1992.

[2] Villanacci V, Antonelli E, Geboes K, Casella G, Bassotti GHistologicalhealing in inflammatory bowel disease: a still unfulfilled promise.World J Gastroenterol2013; 19:968978.

[3] Rubio CA, May I, Slezak PUlcerative colitis in protracted remission. A quantitative scanning electron microscopic study. Dis Colon Rectum1988; 31:939-944.

[4] Rubio CA, Johansson C, Uribe A, Kock YA quantitative method of estimating inflammation in the rectal mucosa. IV. Ulcerative colitis in remission.Scand J Gastroenterol 1984; 19:525530.

[5] Bressenot A, Cahn V, Danese S, PeyrinBiroulet L Microscopic features of colorectal neoplasia in inflammatory bowel diseases. World J Gastroenterol2014; 20:3164-3172.

[6] GlickmanJN, Bousvaros A, Farraye FA, Zholudev A, Friedman S, Wang HH, Leichtner AM, Odze RD Pediatric patients with untreated ulcerative colitis may present initially with unusual morphologic findings. Am J SurgPathol2004; 28:190-197.

[7] Pontte AC, Damião AO, Rosa AMConsensus guidelines for the management of inflammatory bowel disease. ArqGastroenterol2010; 47:313325 .

[8] Christensen B, Hanauer SB, Erlich J, Kassim O, Gibson PR, Turner JR, Hart J, Rubin DTHistologic normalization occurs in ulcerative colitis and is associated with improvedclinicaloutcomes. ClinGastroenterolHe patol2017; 15:1557-1564.

[9] Park S, Abdi T, Gentry M, Laine LHistological Disease Activity as a Predictor of Clinical Relapse Among Patients With Ulcerative Colitis: Systematic Review and Meta-Analysis. Am J Gastroenterol 2016; 111:1692-1701.

[10] Goldstein NS, CinenzaAN.The histopathology of nonsteroidal anti-inflammatory drugassociated colitis. Am J ClinPathol 1998; 110: 622- 628 .

[11] Allen DC, Hamilton PW, Watt PC, Biggart JDArchitectural morphometry in ulcerative colitis with dysplasia.Histopathology1988; 12:611-621. 
[12] Hamilton PW, Bartels PH, Thompson D, Anderson NH, Montironi R, Sloan JM Automated location of dysplastic field in colorectal histology using image texture analysis. J Pathol 1997; 182:68-75.

[13] Ficsor L, Varga VS, Tagscherer A, Tulassay, Mollnar BAutomated classification of inflammation in colon histological sections based on digital microscopy and advanced image analysis Cytometry A2008;73:230-237.

[14] Rubio CACorrupted colonic crypts bordering regenerating mucosal ulcers in ulcerative colitis. In Vivo 2017; 31:669-671.

[15] Riddell RH, Goldman H, Ransohoff DF, Appelman HD, Fenoglio CM, Haggitt RC, Ahren C, Correa P, Hamilton SR, Morson BCDysplasia in inflammatory bowel disease: standardized classification with provisional clinical applications. Hum Pathol1983; 14:931968.

[16] Ludeman L, Warren BF, Shepherd NA The pathology of diverticular disease. Best Pract Res ClinGastroenterol2002; 16:543-562.

[17] Rubio CA, Ásmundsson J, Silva P, Illies C, Hartman J, Kis L Lymphoid aggregates in Crohn's colitis and mucosal immunity. Virchows Arch(2013) 463:637-542.

[18] Nielsen OH, Vainer B, Rask-Madsen JNonIBD and 19on-infectiouscolitis. Nat ClinPractGastroenterolHepatol2008; 5:28-39.

[19] Salmo E, El-Dhuwaib Y, Haboubi NYHistological grading of tumour regression and radiation colitis in locally advanced rectal cancer following neoadjuvant therapy: a critical appraisal. Colorectal Dis 2011; 13:1100-1106.

[20] Rubio CA, Orrego A, Höög A, Porwitz A, Petersson F, Elmberger G, Glaessgen A, Eriksson E, Kanter L, Jaremko G, Egevad L, Laforga J, Liljefors M, Löfdahl B, Norman P, Larsson O, Wanat R, Wejde J, Zickert P, Björk J, Caini S, Palli D, Nesi GQuantitative assessment of the subepithelial collagen band does not increase the accuracy of diagnosis of collagenous colitis. Am J ClinPathol2008; 130:375-381.

[21] Feuerstadt P, Brandt LJ Update on Colon Ischemia: Recent Insights and Advances. Curr Gastroenterol Rep 2015; 17:45-52.

[22] Lee RGThe colitis of Behçet's syndrome Am J SurgPathol;10:888-893.

[23] Rubio CA, Nydahl S“Nonspecific" erosions and ulcers of the colonic mucosa. Dig Dis Sci1994; 39:821-826.

[24] McKenna BJ, Appelman HD Dysplasia can be a pain in the gut. Pathology2002; 34:518-528.

[25] Eaden J, Abrams K, McKay H, Denley H, Mayberry J Inter-observer variation between general and specialist gastrointestinal pathologists when grading dysplasia in ulcerative colitis J Pathol2001; 194:152-157.

[26] Shih I. M., Wang T. L., Traverso G., Romans K., Hamilton S. R., Ben-SassonS., Kinzler K. W., Vogelstein BTop-down morphogenesis of colorectal tumors. Proc Natl AcadSci USA 2001; 98:2640-2645.

[27] Mikami T, Yoshida T, Shiraishi H, Tokuyama W, Motoori T, Okayasu I Bottom-up cell proliferation with cyclin A and p27Kip1 expression in ulcerative colitis-associated dysplasia. PatholInt2006; 56:10-16.

[28] Rubio CA Corrupted colonic crypt fission in carcinogen-treated rats. PLoS One 2017; 12: e0172824.io.

[29] CA, Befrits R, Jaramillo E, Nesi G, Amorosi AVillous and serrated adenomatous growth bordering carcinomas in inflammatory bowel disease.Anticancer Res2000; 20:4761-4764.

[30] Rubio CASerrated neoplasias and de novo carcinomas in ulcerative colitis: a histological study in colectomy specimens. J Gastroenterol Hepatol 2007; 22: 1024-1031.

[31] Lee LH, Iacucci M, Fort Gasia M, Ghosh S, Panaccione R, Urbanski SPrevalence and Anatomic Distribution of Serrated and Adenomatous Lesions in Patients with Inflammatory Bowel Disease.Can J GastroenterolHepatol 2017; 2017:5490803.

[32] Shen J, Gibson JA, Schulte S, Khurana H, Farraye FA, Levine J, Burakoff R, Cerda S, Qazi T, Hamilton M, Srivastava A, Odze RD Clinical, pathologic, and outcome study of hyperplastic and sessile serrated polyps in inflammatory bowel disease. Hum Pathol 2015; 46:1548-1556.

[33] Iacucci M, Hassan C, Fort Gasia M, Urbanski S, Gui X, Eksteen B, Eustace G, Kaplan GG, Panaccione RSerratedadenoma prevalence in inflammatory bowel disease surveillance colonoscopy, and characteristics revealed by chromoendoscopy and virtual chromoendoscopy.Can J GastroenterolHepatol 2014; 28:589-594.

[34] Popp C, Luciana L, Voiosu T, Bastian A, Cioplea M, Micu G, Pop G, Sticlaru L, Bengus A, Voiosu A, Bogdan-Mateescu R Expression Profile of p53 and p21 in Large Bowel Mucosa as Biomarkers of InflammatoryRelatedCarcinogenesis in Ulcerative Colitis Disease Markers2016; 2016:3625279.

[35] Kini AT, Thangaraj KR, Simon E, Shivappagowdar A, Thiagarajan D, Abbas S, Ramachandran A, Venkatraman AAberrant niche signaling in the etiopathogenesis of ulcerative colitis. Inflamm Bowel Dis2015; 21:2549-2561. 
[36] Noffsinger AE, Miller MA, Cusi MV, Fenoglio-Preiser CThe pattern of cell proliferation in neoplastic and nonneoplastic lesions of ulcerative colitis.Cancer1996; 78:2307-2312

[37] Davies JM, Santaolalla R, Abreu MTUse of Cancer Stem Cells to Investigate the Pathogenesis of Colitis-associated Cancer.Inflamm Bowel Dis 2016; 22:976-983.

[38] You XJ, Bryant PJ, Jurnak F, Holcombe RFExpression of Wnt pathway components frizzled and disheveled in colon cancer arising in patients with inflammatory bowel disease.Oncol Rep2007; 18:691-694.

[39] Shenoy AK, Fisher RC, Butterworth EA, Pi L, Chang LJ, Appelman HD, Chang M, Scott EW, Huang EHTransition from colitis to cancer: high Wnt activity sustains the tumorinitiating potential of colon cancer stem cell precursors. Cancer Res 2012; 72:5091-5100.

[40] You J, Nguyen AV, Albers CG, Lin F, Holcombe RFWnt pathway-related gene expression in inflammatory bowel disease. Dig Dis Sci2008; 53:1013-1019.

[41] Hughes KR, Sablitzky F, MahidaYRExpression profiling of Wnt family of genes in normal and inflammatory bowel disease primary human intestinal myofibroblasts and normal human colonic crypt epithelial cells. Inflamm Bowel Dis 2011; 17:213-220.

[42] Varner VD, Nelson CM. Cellular and physical mechanisms of branching morphogenesis. Development. 2014; 141:2750-2759.

Citation: Carlos A Rubio, Lorand Kis, Peter T Schmidt. Systematic Classification of Colonic Crypts with Architectural Distortions Inulcerative Colitis. ARC Journal of Cancer Science 2017; 3(2):13-20. DOI: http://dx.doi.org/10.20431/2455-6009.0302003

Copyright: (C) 2017 Authors. This is an open-access article distributed under the terms of the Creative Commons Attribution License, which permits unrestricted use, distribution, and reproduction in any medium, provided the original author and source are credited. 